\title{
A Study on the Impact of Regional Environments between Vietnam and Taiwan to Taiwanese Manufacturing Firms' R\&D Locational Choices
}

\author{
Cheng-Tao Tsai ${ }^{1, *}$, Wen-Chung Hsu ${ }^{2}$, Chih-Chia Liao ${ }^{3}$, Chou Yeng Han ${ }^{4}$ \\ ${ }^{1}$ Department of International Business Studies, National Chi-Nan University, Taiwan \\ ${ }^{2}$ National Chi-Nan University University, Taiwan \\ ${ }^{3}$ Department of Education Business Studies, National Taichung University of Education, Taiwan \\ ${ }^{4}$ Ph.D. Program in Strategy and Development of Emerging Industries, National Chi-Nan University, Taiwan
}

Received September 9, 2019; Revised March 13, 2020; Accepted March 28, 2020

Copyright $\odot 2020$ by authors, all rights reserved. Authors agree that this article remains permanently open access under the terms of the Creative Commons Attribution License 4.0 International License

\begin{abstract}
This paper analyzes the impact of R\&D locational choices that manufacturing firms in Taiwan take under the differentiation of locational advantages between Vietnam and Taiwan as well as improves some points which are incompletely focused in the same study on Taiwanese firms, the cross-strait, and overweighing case-studies in the past. The empirical evidences bring that the impact of variables to locational distribution of Taiwanese manufacturing firms across the strait is many: locational advantages, the type of R\&D unit, the scale of the market, political conditions, industrial clusters, knowledge flows and R\&D investments. Except for the negative relationship between the scale of market/type of $R \& D$ unit and $R \& D$ locational choices, the rest variables have the positive relationship with $R \& D$ locational choices, which means that, barring that the scale of market in Taiwan is so small that Taiwanese firms choose to set up R\&D spots in Vietnam, other variables in Taiwan are more attractive than those in Vietnam; Taiwan possesses in negligible energies of regional creativity.
\end{abstract}

Keywords

R\&D Locational Choices, Locational Advantages

\section{Introduction}

The competition among countries is a graduation, replaced by the region competition. The more competitive region often plays a significant role in global economic development. The formation of the innovative regional system has become an important factor in inspiring developing innovation. Through the formation of the innovative industrial system, the region's competitive has become an advantaged means. In coping with the globalization and region competition, the globalization of enterprise' production has become trends. Dunning (1980) proposed the Eclectic Paradigm to explain the development of the foreign direct investment. In this paradigm, under the fulfillment of ownership-specific advantage, internalization advantage, and locational advantage, the enterprise will likely to engage foreign direct investment. This will result in the lower of the product cost and the new market region. Along with the eclectic paradigm, many kinds of research proposed the idea that multi-nation corporations utilized their own advantage to engage in global labor division and connection successfully. (Dicken, 1998), and proposed that the impact of region advantage on the globalization of industries. The research and development of the internationalization has shifted from developed countries to other countries other than developed countries such as China, Vietnam, and Taiwan. The phenomenon of research development of internationalization has formed (Amsden et al., 2001). Not only did the multi-nation corporations invest in developing countries, but also developing countries engaged in multi-nation investment. Related studies believed that the selection of the foreign investment of research development has something to do with the location-specific advantage and strategic consideration of the corporation such as economic, resources, the institution policies, the environment of the research and development, the cluster of the industries of the host countries (OECD, 1997; Gao, 2000; Kumar, 2001;). The aforementioned factors mainly targeted the developed countries. What were the considerations when Taiwanese entrepreneurs distributed to regions such as 
Vietnam? This is the first research motivation.

The importance of investigating the internationalization of Taiwanese corporation's research and development has gained its attention gradually. The research angle include the comparison on the network connection on flag-ship level in investing research and development(R\&D) between the two regions, the analysis of the multi-nation corporations' strategic networking of the R\&D of the Taiwanese corporation's subsidiary companies in Vietnamese regions, and the strategic location of the Taiwanese corporation in technology and information industries in Vietnam which indicated that Taiwan realized the importance of internationalization of $R \& D$ in advancing the competitiveness of the organization. Furthermore, under the background of the geographical neighboring, Vietnam often becomes the critical option in location-specific strategic policies domestically and internationally. On the condition that Vietnam and Taiwan are not in a competing position, however, after establishing the R\&D modules in both countries. The environmental discrepancies between the two countries will impact on their location-specific strategic policies which attract the different $R \& D$ modules to enter the regions. This is the second motivation for this research.

Based on the current research foundations, this research proposed a thorough observation of the Taiwanese and Vietnamese $R \& D$ distribution stations in both regions. There are two main focuses: firstly, studies exploring the Taiwanese corporations' selection on Taiwanese corporation investing location in Vietnam mainly focused on the needs of information and technology productions. They underwent the case study research on the individual corporation. Rarely, they paid attention to the R\&D of location-specific selections. Therefore, this study targeted the top 500 manufactures as subjects, analyzed Taiwanese corporations' location-specific selections. In the hope that the result drawn can serve the references for the government to encourage the establishment of $R \& D$ center for domestic corporations. Secondly, studies in the past failed to compare the difference between the Vietnamese and Taiwanese corporations' location-specific selections; therefore, the environmental impact on the location-specific selections remained unknown. This was also the incentive of this study in selecting both regions to be the research field. Based on the location-specific advantage perspectives, this study analyzed the environmental differences between Taiwanese and Vietnamese regions, in order to explore the factors that influenced the on the station of the R\&D centers of Taiwanese corporations. The results of this study can serve the suggestion to provide an improving $R \& D$ environment for the Taiwanese government in order to advance the Taiwanese corporation competitiveness.

With regard to the framework of this study, the second section consists of the research review to analyze the influencing factors on the location-specific selection of the environment, which served the foundation of the theory and the variable sections accordingly. The third section consists of the comparison of the environmental difference between Taiwan and Vietnam. The fourth section consists of the research design and hypotheses. The fifth section consists of the questionnaire design and the sample data analysis. The sixth section is the establishment of empirical modules and to verify the hypotheses. Last, related suggestions were provided.

This study is focusing on the group of Taiwanese businessmen in Vietnam and emphasize the investment issue and the topic of labor relations. How do the Taiwanese businessmen adjust to the new environment and learn about the new market after they leave their dependable local social structures, the business connections, and social resources? Taking what kind of model management strategy in order to make the most profits.

This paper can be the prioritize determinants for Managements starting to evaluating location choice. Second, the listing determinants can be complete consideration when conduction an assessment.

\section{The Location-Specific Advantages and Location-Specific Selection of the R\&D}

The creation of R\&D knowledge has been the top secret of corporations that has centers on parent countries. Since 1980, the internationalization of $R \& D$ has become the trend of corporations. The arrangement of the multi-nation corporations on the R\&D overseas has shifted from the traditional technological transfers to the two-way interactive research on technologies. In order for the corporations to absorb innovative knowledge, to the R\&D products transfer of the parent companies, or to provide technological service overseas, they behaved internationally (Serapio and Dalton, 1999). Aside from the aforementioned incentives, influencing the decision on abroad location-specific selection of the corporations included the location market size, cost, investment environment, policies, and prize policies. Due to the fact that the establishment of the R\&D station, they had to serve the function of encouraging $R \& D$ innovation productions. As a result, they had to pay attention to the development of the local fundamental sciences, the excellence of the research universities, the professional researchers, and the fine infrastructure (Dunning, 1973).

Furthermore, Heimann (2005) proposed the idea that the provision of the domestic cooperation networking of the R\&D will stimulate the internalization of the outside knowledge. Therefore, the R\&D benefits can be maximized. On the other hand, because of the failure to symbolize deliver and to create R\&D knowledge, the discrepancies of the languages, cultures, and societal 
institutions of the parent countries elicited the social access barriers and cognitive obstacles for the foreign investment. While global economic development takes a significant role, this study analyzed the factors for government attract foreign corporation investment, including the broad domestic market size, the government policies and the fine fundamental science foundations, low labor cost, and preferential policies. This study generalized the four following key factors in attracting the foreign investment in location-specific selections. Firstly, there are four key factors regarding the advantage in location-specific section with the host countries. There is the development of fundamental scientific and human resources of $\mathrm{R} \& \mathrm{D}$. The host countries' strength in human resource can be utilized as the Application for the foreign investors to engage in the cooperation activities which will reduce the cost in researching the human resources (Kumar, 2001). Secondly, the environment for R\&D: the host countries' abundant human resources and abundant facilities, the cluster of industries, or the environmental condition has the effect on attracting the establishment of the R\&D centers of foreign investment. Thirdly, the market size: to expand the overseas' market is one of the incentives of $R \& D$ internationalization (Serapio and Dalton, 1999). The larger the market size of the host country, the more competitive it is for the foreign investor. Therefore, it is more attractive for corporations. This has served one of the important factors in attracting the establishment of R\&D centers for foreign investors. Fourthly, the policies factor and the protection of the wisdom property: $R \& D$ is considered the high investing behavior. If the host country can provide free taxation, the establishment of free trade protecting area, or the protection of the pattern rights or wisdom property, this is easier for the foreign investor to establish the R\&D centers. On the other hand, it is possible to elicit societal and trust into obstacle conditions due to the discrepancies of the culture, society, and environment, hinders the willingness of foreign corporations (Lorenzen and Mahnke, 2002).

There are two keys to the corporations. Firstly, investing strategies of corporations on R\&D: when foreign investors Engaged in overseas' $R \& D$, there are two categories in their supply and demand incentives. The necessity purpose was to fulfill the goal of localization of the strategies, support the foreign corporation in the manufacture and sales of the host countries. In the demand side, the purpose was to gain the advanced technology, to search for the $R \& D$ resource that is short for the corporations, to lower the cost for R\&D, and to search for a better environment for their R\&D (Serapio \& Dalton, 1999). Secondly, the R\&D center categories: Ronstadt (1978), based on their functions, categorized into four different types: technology transfer unit, global technology transfer unit, domestic technology transfer unit, and corporate technology transfer unit. In order to fulfill the needs of the abroad subsidiary company in technology, the technology transfer unit refers to a situation where the technology for the parent companies delivered their technologies to the local subsidiaries. Their establishment usually located abroad. Global technology unit's goal mainly develops products that are suitable for overseas' demand; therefore, it is less influenced by the location of the parent companies and the subsidiaries. Domestic technology units usually involved with the foundation of the domestic technologies of the host countries. The main goal was to develop products desirably.

Thus, the key factor in influencing the location-specific selection is a location-specific advantage. The influence of the regional environment on R\&D innovations mainly worked through the approximation effect (Morgan, 1997). Due to the flow of knowledge, the delivery of the flow will be hindered by the distance between places, especially in tacit knowledge. Corporations within the same or neighboring environment tend to interact more and have more opportunities for learning from each other than those of outside the regions.

The operators within the regions, such as manufacturers, schools, and R\&D institutions, encouraged the formation of the uniqueness of the region through the common shared culture, institution, or value and through the accumulations overtimes (Feldman \& Florida, 1994). Furthermore, the industrial policies and government subsidies and institutional subsidies in technology and the provision of the research staff facilitated innovative production from the corporations, and therefore, the R\&D energies were increased, and the advantages were formed as a result of that.

The different advantages in location-specific advantage between Taiwan and Vietnam are in areas, markets, populations, industrial structures, financial structures, the budget involved in R\&Ds, human resources in R\&Ds, and in political institutions. Among them, the institutions, industrial policies, industrial structures, financial structures, and the performance of the regional R\&D development are the important factors in influencing the R\&D output from the corporations.

When this research analyzed the regional environments of Taiwan and Vietnam, it explored the governmental roles, the industrial structures, the financial structures, and the performance of the R\&Ds. In governmental roles, the roles of the public sectors and the executive of its related policies were explored. In industrial structures, the organization of the manufactures, the connection of the network, the professional human resource, and the professionalization of the industries were explored (Glaeser et al., 1992; Henderson et al., 1995). In financial systems, the focus was on the soundness of the financial structures and institutions. In the Performance of the $R \& D s$, the focus was in the quality and the quantity of the human resource staff, the budget involved in the R\&Ds, and the R\&D outputs within the regions. What are the 
differences in the four perspectives aforementioned between Taiwan and Vietnam? Those differences lead to the location-specific selection of Taiwanese and Vietnamese corporations, which were explored in this study. The latter part of this study used the four perspectives aforementioned as the indicators of the comparison between two regions. Nonetheless, those different behaviors drawn from the four perspectives were used to be the selecting variables of the empirical research accordingly.

\section{Research Design and Hypotheses Establishment}

\subsection{Research Design}

This study explored the key factors in influencing the location-specific advantages for Taiwanese and Vietnamese corporations in location-specific selections. From more complete standpoints, the comparisons of Taiwanese and Vietnamese manufactures in location-specific selections were also analyzed. Targeted the 500 top manufacturers in Taiwan and Vietnam, the research field is located both in Taiwan and Vietnam. The data drawn from Taiwanese manufacturers and Vietnamese manufactures regarding the distribution of the factories were also verified. This study took a broad sense to explore the R\&D selections of the manufactures. In incorporating data gained from interviewing the manufactures when undergoing the testing the hypotheses. Adding the findings of this study, the results of this study can serve a solid foundation in the suggestion provision in advancing the competitiveness in Taiwan.

\subsection{The Hypotheses}

The factors in influencing the location-specific selections include the R\&D's human resource staff of the host countries, the development of the fundamental science, the environment of R\&Ds, the market size, institution factor, the protected policies of the wisdom properties, the corporation R\&Ds investing strategies, and the types of the R\&D units (Ronstadt, 1978; Casson and Singh, 1993; Kuemmerle, 1999; Serapio and Dalton, 1999; Kumar, 2001). The aforementioned factors can be categorized into two types: the location-specific advantages of the host countries and the conditions of the corporations.

This study discovered that there are differences between Taiwan and Vietnam, no matter in the governmental roles and industrious structures, the financial systems, and the performance of R\&Ds. The difference in location-specific advantage has the determining effect on the location-specific selection of the manufactures. The difference between the performances of the R\&Ds in the expected region will also have a determining effect on the R\&D's location-specific selections of the corporations.

Lastly, although the conclusion remains unknown regarding the corporations' budget involvement in R\&Ds, the number of the research staff, and types of the industries towards R\&D's location-specific selections. This study verified the result through the analysis. According to the analysis provided earlier, this study drew the hypotheses and stated as follows:

Hypothesis 1:

Taiwanese corporations' R\&D's location-specific selection is influenced by the different regional environmental performance in R\&Ds. In order to test this hypothesis, this study used the "ratio of the budget in GDP," "the number of research staff per ten thousand people," "the number of authorizing patterns per ten thousand people" to be the three variables as variable analysis. The positive correlation of the aforementioned variables and location-specific selection of $R \& D$ are predicted.

Hypothesis 2:

Taiwanese corporations' location-specific selection is determined by the decision making process. In order to test this hypothesis, this study used the questionnaire methods to understand the factors for the corporations in deciding the location-specific selections. Those factors include "the domestic human resource," "domestic market size," "the domestic ability of corporations," "the domestic policy conditions," "the industrial cluster of the industries and competitiveness," and "the domestic knowledge flow and the ability in innovations." There is a positive correlation between the aforementioned variables and the R\&D's location-specific selections.

Hypothesis 3:

The Taiwanese corporations' location-specific selection is determined by the different types of R\&D units. Due to its function, each unit has difference location-specific considerations. Technology units usually located in the subsidiaries overseas. Global technology unit established its location not based on the location of the parent country nor the host country. The corporal technology unit mostly established in the parent country, which is supporting the development of the core technologies of the strategic development of the parent industries.

\section{Questionnaire Design and Sample Data Analysis}

\subsection{Sampling Population Data Analysis}

In order to analyze the determining factors in influencing Taiwanese corporations and Vietnamese Corporations in R\& D's location-specific selections, this study used Taiwanese top 500 corporations in 2011 as 
subjects. The sampling population is mainly metal raw material industries and manufacturers. There are 61 of them, which are $13 \%$ of the whole. The second type of subject consists of 64 electronic industries, which are $12.9 \%$ of all. The questionnaires were mailed out of the participants dating from Apr. $1^{\text {st }}$ to May $10^{\text {th }}, 2012$. There were 116 returned questionnaires with the returning rate of $33.3 \%$. There were 115 corporations with $R \& D$ establishment, 30 corporations without. In the returning samples, the top three corporations with R\&D establishment are electronic industries (16 corporations, $13.42 \%$ ), photo electricity (14 corporations, $12.12 \%$ ), metal and raw materials and related products (11 corporations, 9.52\%), and computer and computer-parts assembly industries (11 corporations, 9.52\%). The top three corporations without R\&D establishment are metal and raw material industries (12 corporations, $8.25 \%$ ), textile industry (3corporations 2.06\%), and electronic industries ( 2 corporations, $1.72 \%$ ).

This indicated that the establishments of R\&D units mostly are high-tech industries such as electronics and photoelectricity industries. Within the subject corporation of this study, there are 42 corporations in tradition industries, with $36.3 \%$ of all. Therefore, the results of this study are not biased towards the high-tech industries. In addition, with the consideration that there could be more than two R\&D establishments within the same corporation, and to exclude the idea that Taiwanese headquarters establishments of Taiwanese corporal R\&D units, the questionnaires were handed out 158 , facing the fact that there were only 126 corporations documented in this study.

\subsection{Questionnaire Design}

There is highly possible that the type of R\&D department and the location-specific decision factor may play an important role in determining the location-specific sections. Therefore, it was incorporated into the questionnaires as question items. Because the differences in regional environment can be compared through the human resource of the region, the market size, the ability in the manufacture, and the cluster of industries and the flow of knowledge. The corporations, when responding to the question items related to the considering factors in R\&D establishments, which contains the implicit meaning of the comparison. As a result, the shortcomings of difficulties in transferring the aforementioned variables into qualitative variable analysis were redeemed. Other data contained information such as the basic information about the corporation, the number of R\&D staff, and the budget involved in the R\&Ds.

The third type of subject is the aerospace industry, and entertainment manufactures consisting only one corporation. In the number of involving staff, there are 7900000 members, which consist of $20.4 \%$ of the whole.
Secondly, in the computer and computer-related industries such as the part assembly industries, there are 590000 members participated, which consisted of $15.2 \%$ of all. The aerospace industry has the least participating rate, the $0.1 \%$ of all, with the 3181 participating members.

\subsection{Sampling Data Analysis}

Within the 158 valid samples, 141 corporations were selecting Taiwan as their R\&D establishments, with $83.9 \%$. There were only 54 corporations Vietnamese selections with $16.07 \%$ as a whole.

\subsection{Taiwanese and Vietnamese Sample Data Analysis}

To analyze data a step further, in the R\&D types, Taiwanese $R \& D$ establishment is mostly within the technology R\&D. There are 191 questionnaires, $56.86 \%$ of the whole. The second type was the R\&D market related; there were 86 questionnaires, with $25.60 \%$. Hence, there are mostly R\&D transfers in applied technology $R \& D$ and market-related R\&Ds.

In location-specific decision factors, 170 questionnaires responded "domestic human resource" considered the key factor in determining the R\&D establishments in Taiwan, which consisted of $50.60 \%$ of the valid samples, followed by the "domestic cluster industries and the industry competitiveness," with 116 questionnaires, with the rate of $34.52 \%$. The last and the least component was the "domestic market size with the least number of considered factors with 54 questionnaires, $16.06 \%$ of the rate. Therefore, it is safe to postulate that Taiwanese corporations consider the human resources of Taiwan, the cluster of the industries, and the industry competitiveness are the main factors in attracting the R\&D establishments.

Regarding the number of staff in R\&Ds, the most majority of corporations selecting Taiwan as their R\&D establishments, there were 60 questionnaires responded "10 staff members or less", with the rate of $17.86 \%$ of total valid samples. The least number of questionnaires responded, "501 or plus staff members," with a rate of $6.25 \%$. In Vietnamese R\&D establishments, the most amount of the R\&D staff members, the majority of respondents are "11-20 staff members", "50-100 staff members", and 101-150 staff members" with ten respondents respectively. Lastly, regarding the budget involved, within the sample in Taiwanese establishment selections, the majority of respondents clustered in "greater than 10000000 , less than 50000000 ". There were 12 questionnaires with the rate of $3.57 \%$ of the total sample. The minority respondents responded, "less than 1000000 ". There was only one respondent with a rate of $0.3 \%$ of the total sample. In Vietnamese R\&D selections, the majority of respondent responded "greater than 5000000 to 10000000 " and "greater than 10000000 , less than 50000000". There were five respondents from each category, with a rate of $1.49 \%$. There were two 
respondents responded that the item "greater than 1000000 to 5000000 " was most selected with a total rate of $0.60 \%$. Hence, comparing to Vietnamese selections, Taiwanese selections tend to involve more budget with the respondent of Taiwanese establishments.

According to the data drawn from the questionnaires, the R\&D samples tend to cluster more in Taiwanese regions. With the limits of the questionnaire data, if tested with the various logistics variables, due to the different numbers of sample sizes between the two regions, the empirical data may elicit bias. In addition, Taiwan and Vietnam are two different types of political and economic institutions. The main purpose of this study was to analyze the regional environment of Taiwan and Vietnam. The differences arise from influencing the determination of the R\&D location-specific selections. Meanwhile, considered the different numbers in Taiwanese and Vietnamese sampling, the R\&D location-specific selections were divided into Taiwan and Vietnam variables, and later empirical testing was undergone. The results achieved the goal of comparing the regional environment of Taiwan and Vietnam. Regarding the determining factor in influencing the location-specific selections was supplemented by the interview with the corporations.

\section{Taiwanese and Vietnamese Location-Specific Selections- The Establishment of Behavioral Modules and Hypotheses Verification}

\subsection{Empirical Modules}

As mentioned earlier, based on the response gained from the questionnaires, due the big difference in the number of sampling lead to the biased result in various logistic variable testing. This study divided location-specific selections into "Taiwan" and "Vietnam" items. Under the circumstances of dependent variables, the data were analyzed through the Logit model. Logit model based on the theoretical and economic foundation that the consumer behavior of individuals' selections. The individual selection model tends to be measured by the referent functions. When decision-makers face with two or more options, they tend to use the maximization of the effectiveness model in decision making. This study used $\mathrm{U}_{\mathrm{i} 1}$ to for "the effectiveness of Taiwanese R\&D establishment." Also, the $\mathrm{U}_{\mathrm{i} 0}$ was used for "the effectiveness of Vietnamese R\&D establishment." The function was stated as follows:

$$
\begin{gathered}
\mathrm{Ui}_{1}=a_{1}+b_{1} x_{i}+c_{1} z_{i}+\varepsilon_{i 1} \\
\mathrm{U}_{\mathrm{i} 0}={ }_{0} 0+b_{0} x_{i}+c_{0}{ }^{z_{i}+\varepsilon_{\mathrm{i} 0}}
\end{gathered}
$$

Corporations only considered possible when the effectiveness of Taiwanese $R \& D$ establishments are greater than the effectiveness of Vietnamese R\&D establishments. They are willing to selection Taiwan. The function was stated as follows:

$$
\begin{gathered}
P\left(U_{i 1}>U_{i 0}\right) P\left(\varepsilon_{i 1}-\varepsilon_{i}>a_{0}-a_{1}+\left(b_{0}-b_{1}\right) x_{i}+\left(c_{0}-\right.\right. \\
\left.\left.c_{1}\right) z_{i}\right) \\
\log [p(y \leq j \mid x) / 1-p(y \leq j \mid x)] \\
\quad=a_{i}+b_{1} x_{1}+b_{2} x_{2}+\ldots .+b_{k} x_{k}
\end{gathered}
$$

$Y$ describes the level of preference in $R \& D$ establishments in Taiwan. $\mathrm{x} \mathrm{k}$ describes the outside explanatory variables, the attributes of the corporations in terms of location-specific selections. Logit models involved the use of Method of Maximum Likelihood to measure the referent value. This method takes consistency and asymptotically efficiency and asymptotically normal into account (Aldrich and Nelson, 1984 ). As a result, biased can be eliminated. In order to achieved non-biased Conditions, the requirement of this sampling should be average or above $(n=100)$. When used in smaller samples, when $\mathrm{n}<100$, the likelihood of biased arises. This study has fulfilled the requirement of this model. In model collation, Likelihood ration index or chi-square test methods were used. Therefore, the explanatory value of collation was understood.

\section{Variable Analysis}

This study stands in the location-specific perspective to analyze the key factors in determining Taiwanese corporations in R\&D establishments. In selecting empirical variables, the data gained through questionnaires relating to Taiwanese and Vietnamese regional environment were presented. The data were presented as tables shown. 
Table 1. Taiwan location choice results table

\begin{tabular}{|l|l|l|l|}
\hline Variable name & Coefficient value & $\mathrm{t}$ & $\mathrm{P}$ \\
\hline R \& D type (technical research and development type) & 2.101 & 1.597 & 0.147 \\
\hline R \& D type ( Market research and development ) & -0.595 & -2.02 & $0.04 * *$ \\
\hline Local human resources & -8.457 & -0.418 & 0.676 \\
\hline Local market size & -8.732 & -1.797 & $0.00^{* *}$ \\
\hline Local manufacturing capacity & 1.457 & 0.553 & 0.582 \\
\hline Local policy conditions & 8.177 & $0.00^{* *}$ \\
\hline Local industry cluster and industrial competitiveness & 6.874 & $0.01^{* *}$ \\
\hline Local knowledge circulation and innovation capabilities & 18.72 & $0.00^{* *}$ \\
\hline R \& D people below 101-500 people & 1.10 & 0.294 \\
\hline More than 501 R \& D people & 4.289 & 1.248 & 0.379 \\
\hline R \& D funding is more than 5 million to less than 50 million Tawan dollars & 3.276 & 0.136 & $0.070^{*}$ \\
\hline R\&D expenditure is more than 50 million Taiwan dollars & 10.291 & 1.038 & $0.001^{* *}$ \\
\hline Industry category & 0.046 & 1.579 & 0.830 \\
\hline R\&D expenditure as a percentage of GDP (\%) & 1.837 & $0.000^{* *}$ \\
\hline Number of R\&D staff & 10.17 & 0.964 & $0.000^{* *}$ \\
\hline Patent approval number & -0.565 & 247.4 & $0.000^{* *}$ \\
\hline$X^{2}$ & 1.464 & -363.2 & $0.000^{* *}$ \\
\hline$R^{2}$ & 296.253 & 159.25 & \\
\hline
\end{tabular}

\section{Conclusions}

This study used location-specific advantages to analyze the discrepancies in Vietnamese performance in R\&Ds. Also, the determining factor in influencing Taiwanese corporations in location-specific selection was explored. With the soundness perspective, the regional advantages of Taiwan and Vietnam were also discussed. Therefore, the comparison of Taiwanese corporation and Vietnamese corporation was made, and the past researches that favored the high-tech industries were also eliminated. Through the empirical results, the key factors determining Taiwanese and Vietnamese corporations in terms of location-specific selections include location-specific advantages, the types of R\&Ds, domestic policy conditions such as knowledge flow and R\&D budgets involved.

Regarding the variables in this study, there was a negative correlation between the "market type R\&D units," "domestic market size." The rest of the variables are presented positive correlations. It indicated that due to the small Taiwanese market size elicits Taiwanese corporations to go to Vietnam to establish "Market R\&D type." The rest of the factors indicated that Taiwan has more attraction towards those of Vietnam. This is also the factor that attracts Taiwanese manufacturers to establish "Technological R\&D models."

According to the result of an interview conducted by this study, there is a tendency of a stable political environment, faultless policies in wisdom property protection and pattern protection, highly train staff in the R\&D department, and the less obstacles in technological interaction and communications. In addition, the legal provision in terms of useful resources was utilized to build a sound environment for the corporations to engage in the innovations of R\&Ds.

Based on the outside factors, and the attempt to protect the core technology, the avoidance of the leakage of the business secrets, Taiwanese corporations tend to establish their "technological R\&Ds departments in Taiwan. The government must come up with ways to maintain the advantages mentioned above in order to attract Taiwanese corporations, even foreign corporations to establish their R\&D units in Taiwan. There are significant differences in governmental roles, the industry structures, the financial systems, and the performance on R\&Ds between Taiwan and those of Vietnam. Even though the Taiwanese population, areas in terms of size are smaller than those of Vietnam. In terms of the performance of R\&Ds, Taiwan presented an outstanding performance. This suggests that regional R\&D's energy in Taiwan was undeniable.

Therefore, our government must realize the importance of R\&D innovations. The development of core technology is a vital key in advancing Taiwanese competitiveness. As a result, the policy in encouraging domestic corporations to establish their R\&D centers in Taiwan. The establishment of R\&D centers not only has an effect on avoiding the risk of outflow of core technology but also has an effect on assisting the transformation of the corporations from $\mathrm{R} \& \mathrm{D}$ types to the development of 
resource- service integration type of corporations. This is also the factor for Taiwan to break through the current predicament, to shift the direction towards advancing the competitiveness of industries. According to the empirical results of this study, there are almost $80 \%$ of Taiwanese corporations willing to establish their "type of technological R\&D" centers in Taiwan. The establishment of R\&D centers in Taiwan not only attracts the global developing experience to Taiwan but also affects Taiwanese corporations overseas supported by the parent R\&D innovations. Hence, the expansion of corporations can be achieved. Therefore, it is very important to suggest the government to keep encouraging corporations to establish R\&D centers. Also, the government must take domestic ability to assist the advancement of the R\&D centers. To encourage the cooperation of domestic corporations and foreign corporations, therefore, the opportunities for advancing domestic R\&D centers can be increased. Therefore, Taiwanese corporations can take more part in global R\&D's network and to take part in the leading roles. Therefore, this trend of internalization of the R\&Ds can be fulfilled. As a result, Taiwanese corporations' competitiveness can be strengthened.

\section{The Limits of the Research}

Vietnam opened the market to the world and adopted the revolutionary policy since the middle of the 1980s. She attracted a lot of foreign direct investments (FDI), especially after passed "The Law of Foreign Investment" in 1987. Taiwan's investment in Vietnam is the second one only after Singapore. Because of garment factories and good channels, Vietnam government developed textile industry preferentially since 1991 . Vietnam became a focal of Taiwan's manufacturing firms. But the empirical evidences only bring that the impact of variables to locational distribution of Taiwanese manufacturing firms across the strait is just in in Vietnam not in the other country.

\section{Future Research Directions}

1. The willingness of Taiwanese firms to set up R \& D institutions in Vietnam 's potential or future market development without affecting the outflow of core technology, because Vietnam may in the future be as Taiwan 's in terms of human resources, industrial clusters and industrial competitiveness. Under the upgrading conditions, the advantage of Taiwanese firms to set up nearby R \& D institutions is a good research direction.

2. The possibility of local technology research and development in Taiwan's advantageous industries may help to improve the competitiveness of Taiwan's home country enterprises.

3. Study the "Eclectic theory" to explain the development or possibility of Taiwan's direct investment in Vietnam or to increase the willingness to set up R\&D institutions.

4. It is possible to further study the possibility of Taiwan and Vietnam setting up R \& D institutions to enhance their competitiveness under the mutually advantageous conditions of human resources, industrial clusters and industrial competitiveness.

\section{REFERENCES}

[1] Aldrich, J. and F. D. Nelson, (1984), Linear Probability, Logit, and Probit Models, Newbury Park, CA: Sage Publications.

[2] Amsden, A., T. Tschang, and A. Goto, 2001, Do Foreign Companies Conduct R\&D in Developing Countries, ADB Institute Working Paper 14, Tokyo Asian Development Bank Institute.

[3] Baptista, B. and P. Swann, (1998), Do Firms in Clusters Innovate More? Research Policy, 27, pp. 525-540.

[4] Cantwell, J., (1992), The Internationalization of Technological Activity and Its Implication for Competitiveness, Technology Management, and International Business Internationalization of $R \& D$ and technology, pp. 75-79.

[5] Casson, M. and S. Singh, (1993), Corporate Research and Development Strategies: The Influence of Firm, Industry, and Country Factor on the Decentralization of $\mathrm{R} \& \mathrm{D}, R \& D$ Management, 23(2), pp. 91-107.

[6] Dicken, P. M. Forsgren, and A. Malmberg, (1994), The local Embeddedness of Transnational Corporations, in Globalization, Institutions and Regional Development in Europe, edited by Amin, A., and Thrift. N. Oxford: Oxford University Press.Dicken, P.,1998, Global Shift, London: Paul Chapman.

[7] Dunning, J. H. (1973), The Determinants of International Production, Oxford Economic Papers, 25(3), pp. 289-386.

[8] Dunning, J. H. (1980), Towards an Eclectic Theory of International Production: Some Empirical Tests, Journal of International Business Studies, 19(1), pp. 9-31.

[9] Feldman, M. P., and R. Florida, (1994), The Geographic Sources of Innovation: Technological Infrastructure and Product Innovation in the United States, Annals of the Association of American Geographer, 84(2), pp. 210-229.

[10] Florida, R., (1995), Toward the Learning Region, Futures, 27(5), pp. 527-536.

[11] Fors, G. and M. Zejan, 1996, Overseas R\&D by Multinationals in Foreign Centers of Excellence, Working Paper no.111, The Economic Research Institute, Estocolmo: Stockholm School of Economics. 
[12] Gao, T., 2000, Multinational Activity and Country Characteristics in OECD countries, Manuscript. Glaeser, E. L., H. D. Kallal, J. A. Scheinkman, and A. Shleifer, 1992, Growth in Cities, The Journal of Political Economy, 100(6), pp. 1126-1152.

[13] Guellec, D. and B. Bruno van Pottelsberghe de la Potterie, 2001, The Internationalization of Technology Analyzed with Patent Data, Research Policy, 30(8), pp. 1253-1266. Heimann, P., 2005, Foreign-owned R\&D Facilities in China, England, Germany, and Sweden: An Analysis of Regional Entry and Integration Behavior, Working Paper, University of Augsburg, Germany, Faculty of Economics.

[14] Henderson, V., A. Kuncoro, and M. Turner, 1995, Industrial Development in Cities, Journal of Political Economy, 103(5), pp. 1067-1090.

[15] Morgan, K., (1997), The Learning Region: Institutions, Innovation and Regional Renewal, Regional Studies, 31(5), pp. 491-503. Nicholas, S., W. Purcell, and S. Gray, 2001, Regional Clusters, Location Tournaments, and Incentives: An Empirical Analysis of Factors Attracting Japanese Investment to Singapore, Asia Pacific Journal of Management, 18(3), pp. 395-405.

[16] OECD, (1997), Globalization of Research and Development: A Business Viewpoint, Paris: OECD.

[17] Petrella, R., (1989), Globalization of Technological Innovation, Technology Analysis \& Strategic Management, 1(4), pp. 393-407. Ronstadt, R. C., 1978, International R\&D: The Establishment and Evolution of Research and Development Abroad by Seven U.S. Multinationals, Journal of International Business Studies, 9, pp. 7-24.

[18] Serapio, M. G., and D.H. Dalton, (1999), Globalization of Industrial R\&D: An Examination of Foreign Direct Investments in $R \& D$ in the United States, Research Policy, 28, pp. 303-316.

[19] Sigurdson, J., 2006, Technological Superpower China, Edward Elgar, Cheltenham, UK, Northampton, MA, USA. Simmie, J., 2005, Innovation and Space: A Critical Review of the Literature, Regional Studies, 39(6), pp. 789-804. 